\title{
Mandibular angle augmentation using solid silicone implants
}

\section{Zwiększenie kąta żuchwy przy użyciu stałych implantów silikonowych}

\author{
Badr Al-Jandan ${ }^{1, A-F}$, Hesham Fathi Marei ${ }^{1,2, C-F}$ \\ ${ }^{1}$ Department of Biomedical Dental Sciences, College of Dentistry, Imam Abdulrahman Bin Faisal University, Dammam, Saudi Arabia \\ ${ }^{2}$ Department of Oral and Maxillofacial Surgery, Faculty of Dentistry, Suez Canal University, Ismailia, Egypt \\ A - research concept and design; $\mathrm{B}$ - collection and/or assembly of data; $\mathrm{C}$ - data analysis and interpretation; \\ $D$ - writing the article; $E$ - critical revision of the article; $F$ - final approval of the article
}

Address for correspondence

Hesham F. Marei

E-mail: hesham.marei@yahoo.com

\section{Funding sources}

None declared

Conflict of interest

None declared

Acknowledgements

The author would like to thank the hospital staff who assisted during the surgeries.

Received on September 9, 2018

Reviewed on 0ctober 8, 2018

Accepted on November 2, 2018

Published online on December 27, 2018

Cite as

Al-Jandan B, Marei HF. Mandibular angle augmentation using solid silicone implants [published online as ahead of print on December 27, 2018]. Dent Med Probl. 2018;55(4):367-370. doi:10.17219/dmp/99531

DOI

$10.17219 / \mathrm{dmp} / 99531$

Copyright

○ 2018 by Wroclaw Medical University

and Polish Dental Society

This is an article distributed under the terms of the

Creative Commons Attribution Non-Commercial License

(http://creativecommons.org/licenses/by-nc-nd/4.0/)

\begin{abstract}
Background. The demand for facial esthetics has increased dramatically to overcome the ongoing aging process and/or improve facial appearance.

Objectives. The aim of this study was to evaluate the outcomes of using bilateral silicone implants for mandibular angle augmentation.

Material and methods. The study involved a prospective analysis of the outcomes of the mandibular angle region augmentation with bilateral silicone implants in 58 patients ( 2 males and 56 females) within 1 year. All the data was collected either from patients' interviews or their records, after receiving the ethical approval from the relevant hospital. The collected patients' data was analyzed based on 3 main outcomes: occurrence of implant displacement, presence of postoperative infection and patient satisfaction. Only the patients who completed a follow-up of 6 months postoperatively were included in this study.

Results. A total of 58 patients received bilateral silicone implants at the mandibular angle with a total of 116 implants, out of which 96 were found intact, with no evidence of complications. The total number of implants that were infected was 5 (4.3\%), 16 implants were found displaced (13.8\%) and only 3 patients of those without complications were dissatisfied with the final facial appearance (6\%).

Conclusions. Using solid silicone implants in the augmentation of the mandibular angle resulted in low postoperative infection and displacement rates, as well as in high patient satisfaction.
\end{abstract}

Key words: reconstructive surgery, solid silicone implants, mandibular angle augmentation Słowa kluczowe: chirurgia plastyczna, stałe implanty silikonowe, zwiększenie kąta żuchwy 


\section{Introduction}

The demand for facial esthetics has increased dramatically to overcome the ongoing aging process and/or improve facial appearance. ${ }^{1}$ With aging, changes occur in the face - the mandibular angle becomes greater in edentulous people as compared to the dentate ones, ${ }^{2}$ which may lead to the sagging of the mandibular jowl area.

In the literature, there is a lack of cephalometric and clinical examination standards to evaluate the ideal mandibular angle length and projections. However, some of the favorable radiographic and clinical features of the ideal mandibular angle are as follows: the angle of the jaw should be long and low in profile, $<105^{\circ}$ when measuring the slope of the lower border and the ascending ramus on a lateral cephalometric radiograph. Clinically, frontal examination should show an equal bigonial and bitemporal distance in order to have the mandibular angle welldefined and easily noticeable from the neckline., ${ }^{3,4}$

The mandibular angle is an essential part of the skeletal framework; therefore, its correction plays an important role in maintaining and improving facial esthetics. ${ }^{4}$ Multiple techniques and approaches have been described in the literature to address the sagging of the mandibular jowl area, with variable success rates. These techniques involve the injection of temporary fillers or the surgical placement of permanent alloplastic materials, such as polytetrafluoroethylene (PTFE) and solid silicone implants. Temporary fillers approved by the Food and Drug Administration (FDA) include collagen, hyaluronic acid, calcium hydroxyapatite, and polylactic acid. In the case of hyaluronic acid, the results are reversible with hyaluronidase. Although both PTFE and silicone implant materials are considered as inert permanent alloplastic materials, each one carries its indications, risks and benefits. ${ }^{5-7}$

Solid silicone (dimethylsiloxane, $\left.\mathrm{SiO}\left(\mathrm{CH}_{3}\right)_{2}\right)$ implants are easy to handle, have increased flexibility, can be sculpted, ${ }^{8}$ and thus can be placed at the lateral mandibular ramus using small incisions. It has improved bone adaptability, which makes it easier to stabilize with titanium (Ti) screws. In contrast, a PTFE implant is rigid and stiff, and does not bend. Therefore, placing it in the bone requires larger incisions. Moreover, due to the stiff nature of PTFE, it is difficult to passively adapt it at the lateral mandibular ramus, so there are problems with stabilizing it. ${ }^{9}$ Furthermore, the surface porosity of PTFE enables the soft tissue growth into the implant, which makes the implant difficult to remove, if indicated in the future. On the other hand, silicone implants create a capsule around them, which makes their removal easier, if needed. ${ }^{9}$

The surgical placement of silicone implants involves general complications, such as infection, seroma and hematoma. Moreover, in the cases of non-stabilized silicone implants, implant displacement and bone resorption were reported. ${ }^{10,11}$ Currently, there is no consensus regarding the stabilization of implants and the required fixation devices ( $\mathrm{Ti}$ screws vs non-resorbable sutures). It might be due to the fact that there are multiple specialists (maxillofacial, plastic, and head and neck) with a diverse training background referring to such a service. Maxillofacial surgeons tend to use screws for stabilization, whereas plastic surgeons commonly use sutures for stabilization, as indicated by previous studies..$^{9,12}$

Since there is a deficit of studies that have analyzed the performance of silicone implants in the mandibular angle region, the aim of this study was to evaluate the outcomes of mandibular angle augmentation with the use of a silicone implant through a prospective evaluation of patients in regard to implant displacement, infection and patient satisfaction.

\section{Material and methods}

The study involved a prospective analysis of the records of 58 consecutive patients ( 2 males and 56 females), who had received bilateral silicone implants at the mandibular angle region within 1 year in 2 different hospitals. All the data was collected either from patients' interviews or from a specific data sheet that had been designed for this study. The data was collected after receiving the ethical approval from the relevant hospital. The inclusion criteria were as follows:

- the patient had been diagnosed with ill-defined mandibular angles and a narrow face;

- silicone implants were placed at the mandibular angle;

- the patient was medically fit;

- the patient was followed up for at least 6 months after the surgery.

All the patients received the surgical procedure by the same surgeon and the same surgical protocols were followed. All the procedures were performed under general anesthesia with nasoendotracheal intubation. Approximately $10 \mathrm{~mL}$ of $2 \%$ lidocaine with 1:100,000 epinephrine was injected along the incision site. A 1.5-centimeter incision was made $1 \mathrm{~cm}$ lateral to the external oblique ridge of the mandible. Next, subperiosteal dissection was performed to expose the lateral ramus of the mandible and superiorly to the level of the sigmoid notch. The entire lateral and inferior surface of the mandibular ramus was then exposed. A curved freer elevator instrument was used to disrupt the pterygo-masseteric sling at the inferior border of the mandible and to allow the silicone angle implant (Hanson Medical Inc., Kingston, USA) to be adapted easily below the inferior border and behind the posterior border of the mandible. The silicone implant was stabilized using 2 monocortical screws of $2 \times 7 \mathrm{~mm}$ (Fig. 1). The wound was then irrigated with antibiotic solution (Gentamicin ${ }^{\circledR}$, $40 \mathrm{mg}$ in $100 \mathrm{~mL}$ solution) and closed with 2 layers using 4/0 Vicryl ${ }^{\circledR}$ sutures (Ethicon, Inc., Bridgewater, USA). 

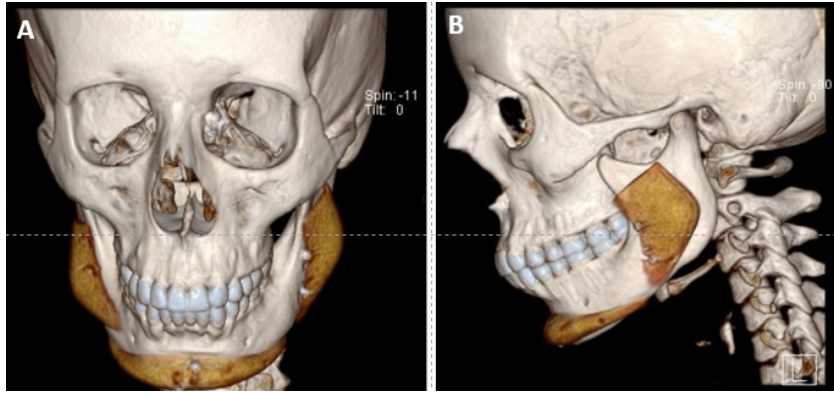

Fig. 1. Three-dimensional cone beam computed tomogram showing a solid silicone implant placed at the mandibular angle

A - frontal view; B - lateral view.

All the patients were administered Augmentin ${ }^{\circledR}(1 \mathrm{~g}$ twice daily for 1 week), Ibuprofen ${ }^{\circledR}$ (600 mg 4 times daily for 1 week) and chlorohexidine mouthwash for 2 weeks. The patients were reviewed according to the following protocol:

- the $1^{\text {st }}$ follow up: 1-2 weeks;

- the $2^{\text {nd }}$ follow-up: $3-4$ weeks;

- the $3^{\text {rd }}$ follow-up: 2-3 months;

- and the last follow-up: 6 months postoperatively.

During the follow-up visits, patients were evaluated by a second examiner (maxillofacial surgeon) for the following parameters:

- infection, which was demonstrated by fluctuation and pus discharge from the incision line;

- displacement of the silicone implant, which was established on the basis of facial asymmetry that was noticed by the patient and/or reported during examination by the surgeon;

- and satisfaction, which was reported by the patients as either 'yes' or 'no' after 6 months. Patient satisfaction was mainly based on the fulfillment of their expectations about the proposed treatment.

\section{Results}

In this study, a total of 58 patients ( 2 males and 56 females) received bilateral implant placement at the mandibular angle (Fig. 2) with a total of 116 implants, out of which 96 were found intact, with no evidence of complications.

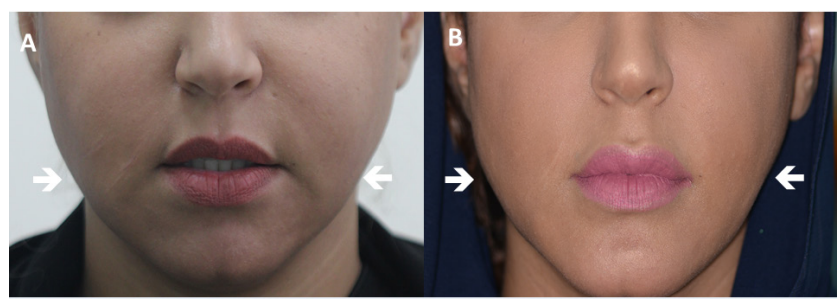

Fig. 2. A - preoperative frontal view; B - postoperative frontal view after submental liposuction, mandibular angle and chin augmentation using a solid silicone implant
Five implants in 3 different patients were infected; 4 of them had to be removed and 1 resolved after antimicrobial therapy and daily local wound care. The overall incidence of infection was $4.3 \%$.

The total number of displaced implants was 16 in 8 patients, of which half required removal only and the other half required removal and replacement by another implant. The overall incidence of displacement was $13.8 \%$.

In regard to patient satisfaction, only 3 patients out of those without complications $(n=50)$ were dissatisfied with the final outcome, with an overall satisfaction rate of $94 \%$. Dissatisfied patients had intact mandibular angle implants with adequate facial symmetry, but still found that their expectations were not met.

\section{Discussion}

The current study investigated data of 58 patients who received 116 silicone implants by 1 surgeon following the same surgical protocol within 1 year with at least 6 months of follow-up. In an earlier study, it was reported that one of the complications associated with silicone implants was underlying passive bone remodeling and this claim was supported by the presentation of 4 cases of bone resorption after alloplastic chin augmentation (in 2 of them, silicone implants were used). ${ }^{13}$ The probable reason of such a complication might be the fact that the implants were not stabilized with screws, which could lead to continuous micro-movement, and consequently to bone resorption. ${ }^{10}$ In contrast, our study involved the stabilization of all the implants utilizing monocortical fixation screws, which was recommended previously. ${ }^{9}$ Passive bone remodeling is a common process that occurs at the early stages after solid silicone implants have been placed, when the body attempts to confine the implants into the facial skeleton. However, this process might be continuous if the implants are not stabilized. ${ }^{10}$ Absolute fixation of solid implants via a transoral approach requires the placement of at least 1 screw at each corner of the implant, which is clinically unachievable in such a way. However, this can be achieved via a transcutaneous approach, which may in turn carry unfavorable cosmetic outcomes. In addition, it makes the elective removal process quite complex if the patient is unsatisfied.

Ridwan-Pramana et al. placed 27 PTFE implants at the mandibular angle region and reported that 3 patients presented with infection (27\%) and 2 patients remained unsatisfied with the outcome (18.2\%). ${ }^{5}$ By contrast, in our study, which had a 3 times bigger sample size, only 3 patients developed infection (4.3\%) and only 3 patients were dissatisfied (6\%). This is most likely due to the fact that the rigid and non-fixable nature of PTFE implants makes it difficult to place them and achieve good adaptation, whereas silicone implants are flexible, ${ }^{8}$ and therefore can be properly adapted, leading to better patient satisfaction. 
Previously, a review of 24 PTFE implants placed at the mandibular angle reported no infection from any implant and 1 implant (4.16\%) got displaced. ${ }^{13}$ Aynehchi et al. reported no displacement or infection in 105 patients who underwent the placement of silicone implants transorally via a vertical concise incision at the chin region with no fixation, over at least 1-year follow-up period. ${ }^{14}$ Moreover, Gui et al. reported on 150 porous polyethylene implants (Medpore ${ }^{\circledR}$ ) placed in the chin transorally and fixated with a screw. They observed no displacement during a follow-up from 6 months to 6 years. ${ }^{15}$ In contrast to the abovementioned studies, the displacement rate in our study was $13.8 \%$. The different rate of displacement could be due to the fact that the displacement of a facial implant is site-dependent and may vary according to the surrounding soft tissue, musculature and masticatory forces in this area. ${ }^{16}$ Since there are high masticatory forces in the angle as compared to the chin region, the implant displacement rate in our study was higher than the reported displacement rate in the chin region.

Our study is not without limitations. It involved 58 patients who received only 1 type of facial implants and were followed up for a limited time. The literature would benefit from controlled studies comparing silicone implants with 2 or more types of facial implants at different facial regions. Within the limitation of this study, we found that bilateral silicone implants, when placed through concise transoral incisions and stabilized with 2 monocortical Ti screws, are an appropriate material that can augment the mandibular angle region with minimal complications and high patient satisfaction.

\section{Conclusions}

Low incidence of postoperative infections and a low displacement rate, along with high patient satisfaction were observed in the augmentation of bilateral mandibular angles with solid silicone implants.

\section{References}

1. D'souza R, Kini A, D'souza H, Shetty N, Shetty O. Enhancing facial aesthetics with muscle retraining exercises - a review. J Clin Diagn Res. 2014;8:9-11.

2. Engstrom C, Hollender L, Lindqvist S. Jaw morphology in edentulous individuals: A radiographic cephalometric study. J Oral Rehabil. 1985;12:451-460.

3. Ousterhout DK. Mandibular angle augmentation and reduction. Clin Plast Surg. 1991;18:153-161.

4. Aiache AE. Mandibular angle implants. Aesthetic Plast Surg. 1992;16:349-354.

5. Ridwan-Pramana A, Wolff J, Raziei A, Ashton-James CE, Forouzanfar T. Porous polyethylene implants in facial reconstruction: Outcome and complications. J Craniomaxillofac Surg. 2015;43:1330-1334.

6. Binder WJ, Azizzadeh B. Malar and submalar augmentation. Facial Plast Surg Clin North Am. 2008;16:11-32.

7. Constantinides MS, Galli SK, Miller PJ, Adamson PA. Malar, submalar, and midfacial implants. Facial Plast Surg. 2000;16:35-44.

8. Anger J, Alcalde RF, de Campos JR. The use of soft silicone solid implant molded intraoperatively for pectus excavatum surgical repair. Einstein (São Paulo). 2014;12:186-190.
9. Niamtu J III. Cosmetic Facial Surgery. $1^{\text {st }}$ ed. London, UK: Elsevier; 2011:369-433.

10. Polo M. Bone resorption under chin implants: The orthodontist's role in its diagnosis and management. Am J Orthod Dentofacial Orthop. 2017;151:201-208.

11. Hasson O, Levi G, Conley R. Late infections associated with alloplastic facial implants. J Oral Maxillofac Surg. 2007;65:321-323.

12. Terino EO, Edwards MC. Customizing jawlines: The art of alloplastic premandible contouring. Facial Plast Surg Clin North Am. 2008;16:99-122.

13. Yaremchuck MJ. Facial skeletal reconstruction using porous polyethylene implants. Plast Reconstr Surg. 2003;111:1818-1827.

14. Aynehchi BB, Burstein DH, Parhiscar A, Erlich MA. Vertical incision intraoral silicone chin augmentation. Otolaryngol Head Neck Surg. 2012;146:553-559.

15. Gui L, Huang L, Zhang Z. Genioplasty and chin augmentation with Medpore implants: A report of 650 cases. Aesthetic Plast Surg. 2008;32:220-226.

16. Carboni A, Cerulli G, Perugini M, Renzi G, Becelli R. Long-term follow-up of 105 porous polyethylene implants used to correct facial deformity. Eur J Plast Surg. 2002;25:310-314. 